\title{
BMJ Open Observational study of vascular dementia in the Spanish elderly population according to type 2 diabetes status: trends in incidence, characteristics and outcomes (2004-2013)
}

\author{
Nuria Muñoz-Rivas, ${ }^{1}$ Manuel Méndez-Bailón, ${ }^{2}$ José M de Miguel-Yanes, ${ }^{3}$ \\ Valentín Hernández-Barrera, ${ }^{4}$ Javier de Miguel-Díez, ${ }^{5}$ Rodrigo Jimenez-Garcia, ${ }^{4}$ \\ Ana López-de-Andrés ${ }^{4}$
}

To cite: Muñoz-Rivas N, Méndez-Bailón M, Miguel-Yanes JMde, et al. Observational study of vascular dementia in the Spanish elderly population according to type 2 diabetes status: trends in incidence, characteristics and outcomes (2004-2013). BMJ Open 2017;7:e016390. doi:10.1136/ bmjopen-2017-016390

- Prepublication history and additional material for this paper are available online. To view these files please visit the journal online (http://dx.doi. org/10.1136/bmjopen-2017016390).

RJ-G and AL--A contributed equally.

Received 10 February 2017 Revised 22 March 2017 Accepted 5 May 2017

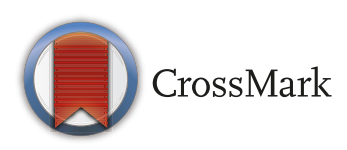

For numbered affiliations see end of article.

Correspondence to Dr Rodrigo Jimenez-Garcia; rodrigo.jimenez@urjc.es

\section{ABSTRACT}

Objectives To examine trends overtime in the incidence and in-hospital outcomes of vascular dementia (VaD) hospitalisations in patients aged 70 years or over suffering and not suffering from type 2 diabetes mellitus (T2DM) between 2004 and 2013 in Spain.

Design Retrospective study.

Setting Spain.

Participants National hospital discharge data were used; patients aged $\geq 70$, discharged from a hospital with $\mathrm{VaD}$ as a primary diagnosis, were selected.

Main outcome measures Overall incidence, therapeutic and diagnostic procedures, comorbidities, infectious complications, duration of hospital stays and in-hospital mortality (IHM).

Results In total, 170607 admissions for $\mathrm{VaD}(34.3 \%$ with T2DM) were identified. We found a significant upward linear trend in the incidence of $\mathrm{VaD}$ for men and women with and without diabetes between 2004 and 2013. The adjusted incidence was higher among people with T2DM over the study period. We found a higher incidence in men than women in all years under study. A positive association between T2DM and $\mathrm{VaD}$ hospitalisation was found among both men (IRR $2.14,95 \% \mathrm{Cl} 2.11$ to 2.16 ) and women (incidence rate ratio (IRR) 2.22; $95 \% \mathrm{Cl} 2.19$ to 2.25). Pneumonia was significantly associated with a higher mortality (OR $2.59,95 \% \mathrm{Cl} 2.52$ to 2.67$)$. We found that percutaneous endoscopic gastrostomy was associated with lower IHM (OR $0.37,95 \% \mathrm{Cl} 0.31$ to 0.45 ), while parenteral nutrition had the opposite effect (OR 1.29, $95 \% \mathrm{Cl} 1.18$ to 1.41). There was no association between diabetes and higher IHM (OR $0.99,95 \% \mathrm{Cl} 0.93$ to 1.06). The time-trend analyses of the entire sample showed a significant reduction in mortality in patients with $\mathrm{VaD}(\mathrm{OR}$ $0.98,95 \% \mathrm{Cl} 0.97$ to 0.99 ).

Conclusions Incidence rates for VaD hospitalisations were twice as high in patients with diabetes compared with those without. Men had significantly higher incidence rates than women, regardless of diabetes status. In both groups studied, pneumonia and parenteral nutrition were associated with mortality while percutaneous endoscopic gastrostomy was associated with survival. Having diabetes

\section{Strengths and limitations of this study}

- The study strengths include the 10-year followup, a very large sample size and standardised methodological approach.

- A limitation is the lack of information on $\mathrm{VaD}$ or type 2 diabetes mellitus duration, treatments for this last condition or sociodemographic characteristic.

- Another limitation is the lack of specificity of clinically defined vascular dementia.

was not associated with higher IHM after hospitalisation with $\mathrm{VaD}$.

\section{INTRODUCTION}

Dementia has become a serious public health burden on a global level, accompanied by significant financial and social implications. ${ }^{1}{ }^{2}$ Vascular dementia (VaD) and Alzheimer's disease (AD) are the most common forms of dementia, which together account for more than $90 \%$ of all cases. ${ }^{1}$

According to several epidemiological studies, patients with diabetes are at an increased risk for stroke, lacunar infarcts, AD and $\mathrm{VaD}^{3-5}$ through amyloid- $\beta /$ tau-dependent and independent mechanisms. ${ }^{3}$

On a global scale, over 300 million people are affected by type 2 diabetes mellitus (T2DM). ${ }^{6}$ This has been associated with an increased risk of macrovascular and microvascular complications, and it also constitutes an independent risk factor for vascular dementia ${ }^{78}$ and $\mathrm{AD} .{ }^{9}$ Furthermore, recent reports suggest that patients with diabetes have a $60 \%$ higher risk for developing dementia. $^{10}$ Age, smoking, hypertension and diabetes, all represent factors linked to 
dementia, therefore it is only to be expected that hospitalisation for $\mathrm{VaD}$ will increase in the coming years. ${ }^{11} 12$ Hence, we identified the need to study the evolution of $\mathrm{VaD}$ over time and to determine the factors and procedures which could result in a higher in-hospital mortality (IHM).

National hospital discharge data were used in this study to analyse linear trends in the incidence of $\mathrm{VaD}$ among hospitalised men and women with and without T2DM between 2004 and 2013 in Spain. Specifically, we analysed linear trends in the utilisation of therapeutic and diagnostic procedures, comorbidities, common infectious and medical complications and in-hospital outcomes such as length of hospital stay (LOHS), readmission rates and IHM.

\section{METHODS}

This was a retrospective, observational study, conducted based on the records of the Spanish National Hospital Database (CMBD, Conjunto Minimo Básico de Datos). ${ }^{13}$ We included all patients aged $\geq 70$ years hospitalised for VaD (International Classification of Diseases, Ninth Revision, Clinical Modification (ICD-9-CM) codes: 290.40, $290.41,290.42,290.43)$ in the first diagnosis position between 1 January 2004 and 31 December 2013.

We compared those suffering T2DM (codes: 250.x0; 250.x2) in any diagnosis position (2 to 14) and those without diabetes.

We estimated the adjusted incidence of discharge rates after $\mathrm{VaD}$ for women and men according to the presence of T2DM per 100000 inhabitants, as described in detail in the online supplementary methods.

Clinical variables included comorbidity suffered at the time of discharge, which was evaluated using the Charlson Comorbidity Index $(\mathrm{CCI})^{14}$ as described in detail in the online supplementary methods.

We specifically analysed the presence of previous stroke (ICD-9-CM codes 430.x, 431.x, 433.x1, 434.x1, 435.x, 436, and 362.3), hypertension (codes: 401, 401.0, 401.1, 401.9) and atrial fibrillation (code: 427.31) in any diagnosis position during vascular dementia hospitalisation. We also identified common infectious complications such as pneumonia (codes: 480-488, 507.0-507.8) and urinary tract infection (codes: 590.0, 590.9, 595.0, 595.9, 597.80, $599.0)$. We analysed other medical complications, specifically agitation (code: 307.9) and malnutrition (code: 263.9).

We also analysed therapeutic and diagnostic procedures including: MRI (code: 88.91), CT angiography (CAT) (code: 87.03), percutaneous endoscopic gastrostomy (PEG) (code: 43.11), mechanical ventilation (codes: 96.7; 96.70; 96.71; 96.72), parenteral nutrition (codes: 99.15) and bladder catheterisation (code: 57.94).

The variable readmission includes those patients who had been discharged from the same hospital in the previous 30 days of admission for $\mathrm{VaD}$ (30 day readmission). Furthermore, the mean number of days of hospitalisation (LOHS) and the number of patients who died in the hospital divided by all the discharges (IHM) were calculated for each year.

The statistical analysis is described in the online supplementary methods.

\section{ETHICS}

In accordance with Spanish legislation, confidentiality of data was ensured during all stages of the study. Patient anonymity was protected by removal of potentially identifying information before the database was accessed by the authors. Thus, it is impossible to identify individual patients, either in this paper or in the database. Informed consent was deemed unnecessary by the Spanish legislation, because of the anonymous and mandatory characteristics of data. The ethics committee of the Universidad Rey Juan Carlos approved the study protocol.

\section{RESULTS}

In total, 170607 discharges were identified (78499 men and 92108 women) of patients suffering $\mathrm{VaD}$ as the primary diagnosis. T2DM was reported in $34.3 \%$ of the total. The prevalence of T2DM in men with VaD showed a significant increase from $28.94 \%$ in 2004 to $34.58 \%$ in $2013(\mathrm{p}<0.01)$. The prevalence of T2DM in women with $\mathrm{VaD}$ increased from $34.13 \%$ to $35.37 \%$ ( $\mathrm{p}<0.01)$.

The overall adjusted incidence of admissions for $\mathrm{VaD}$ was higher among the oldest subgroup ( $\geq 85$ years), both in men and women, with or without diabetes. In patients with T2DM older than 85 years, we found that incidence rates were 1369.63 per 100000 inhabitants in women and 1308.71 per 100000 inhabitants in men. In the non-diabetic group, incidence rates for men and women were 776.52 and 824.15 per 100000 inhabitants, respectively (see online supplementary table).

A significant increase in the adjusted incidence rate of admissions for VaD was found in men with T2DM aged $\geq 85$ years old (1191.79 cases per 100000 inhabitants in 2004 to 1393.17 cases in 2013) but not in women (see online supplementary table).

As can be seen in table 1 , the mean age was 80.72 years (SD, 5.65 years) in men with diabetes and 82.4 years (SD, 5.93 years) in men without diabetes. According to the CCI, $40.86 \%$ of men with T2DM had three or more coexisting conditions; in men without this disease it was $39.3 \%$. The proportion of men with T2DM with $\geq 2$ coexisting conditions was a little higher than that of men without diabetes $(81 \%$ vs $79.71 \%)$.

The prevalence of previous stroke among men with and without diabetes was similar and near to $50 \%$ in all years analysed and rose significantly over time $(p<0.001)$ from around $46 \%$ to $52 \%$ in both groups of patients. A significantly greater prevalence of hypertension was found in men with diabetes compared with men without diabetes $(49.69 \%$ and $37.31 \%$, respectively); however, 


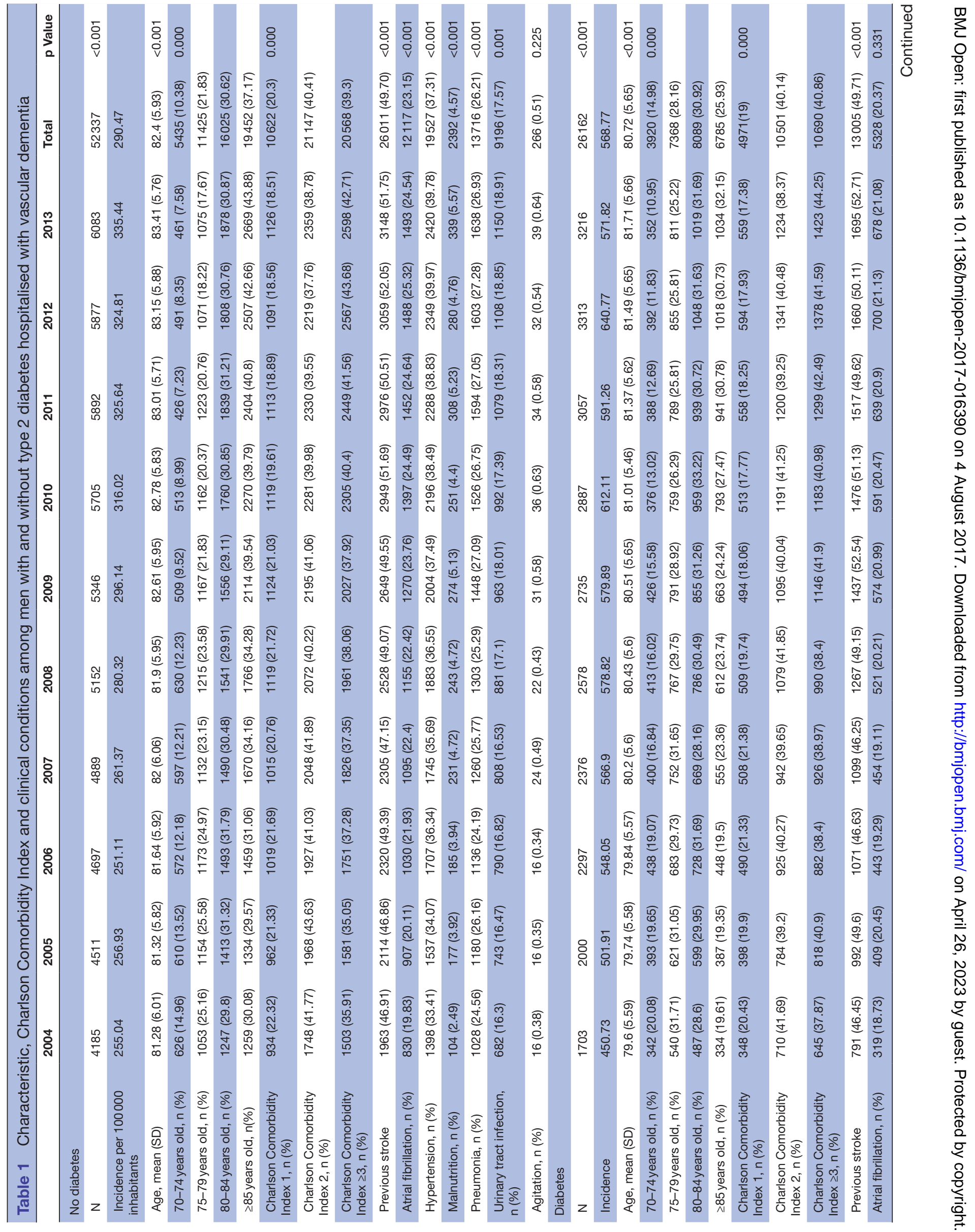


atrial fibrillation, malnutrition, pneumonia and agitation were more frequent in men without diabetes (table 1).

From 2004 to 2014, the estimated adjusted incidence of discharges due to VaD raised significantly from 450.73 cases to 571.82 among men with diabetes and from 255.04 cases to 335.44 cases among men without diabetes. The rates were higher among men with diabetes than men without in all the years analysed (table 1).

Table 1 shows a significant increase in age, CCI and hypertension prevalence, observed over the study period, in both groups.

We found that the proportion of patients with malnutrition has significantly increased over time, ranging from $2.49 \%$ in 2004 to $5.57 \%$ in 2013 in men without T2DM, and from $2.41 \%$ to $3.64 \%$ in those with diabetes over the study period $(\mathrm{p}<0.05)$. In both men with and without diabetes, we found that pneumonia increased significantly over time. In men without diabetes, urinary tract infections increased from $16.3 \%$ to $18.91 \%$ ( $\mathrm{p}<00.5)$; however, in men with diabetes, this infectious complication remained stable. Agitation has not changed over time in any group (table 1 ).

Over the study period, $54 \%$ of all VaD hospitalisations were women. Women with T2DM were significantly younger than women without diabetes $(83.17$ years vs 85.01 years) and had higher CCI values $(29.21 \%$ and $26.8 \%$ with $\geq 3$ coexisting conditions) (table 2 ).

Among women, the overall prevalence of previous stroke was significantly higher for those with and without diabetes $(49.12 \%$ vs $47.71 \%)$. Only among women without diabetes a significant increase was found from 2004 to 2013. Women with diabetes were more prone to hypertension compared with women without T2DM $(57.07 \%$ vs $46.05 \%$ ). However, the prevalence of atrial fibrillation was higher in women without diabetes than in women with diabetes $(27.67 \%$ vs $26.75 \%)$ (table 2 ).

The incidence rate of hospitalisation among women with T2DM rose significantly over the study period from 410.63 cases per 100000 women with diabetes to 477.63 , as shown in table 2. Incidence rates increased from 192.92 cases to 266.76 cases $(p<0.05)$ among women without diabetes. Rates were higher in women with diabetes in all years analysed.

Beside diabetes status age, comorbidity and the prevalence hypertension and atrial fibrillation increased significantly from 2004 to 2013. We found an increase in the prevalence of malnutrition, pneumonia and urinary tract infections during hospitalisation in both groups (table 2).

The comparison between men and women with diabetes reveals that men have a higher adjusted incidence rate than women, in all years covered by this study. Men with diabetes are significantly younger $(80.72$ vs 83.17 years $)$ and have a CCI $\geq 3,(40.86 \%$ vs $29.21 \%)$ more frequently than women. Women with diabetes suffered more atrial fibrillation ( $26.75 \%$ vs $20.37 \%$ ) and hypertension $(57.07 \%$ vs $49.69 \%)$ than men without. 


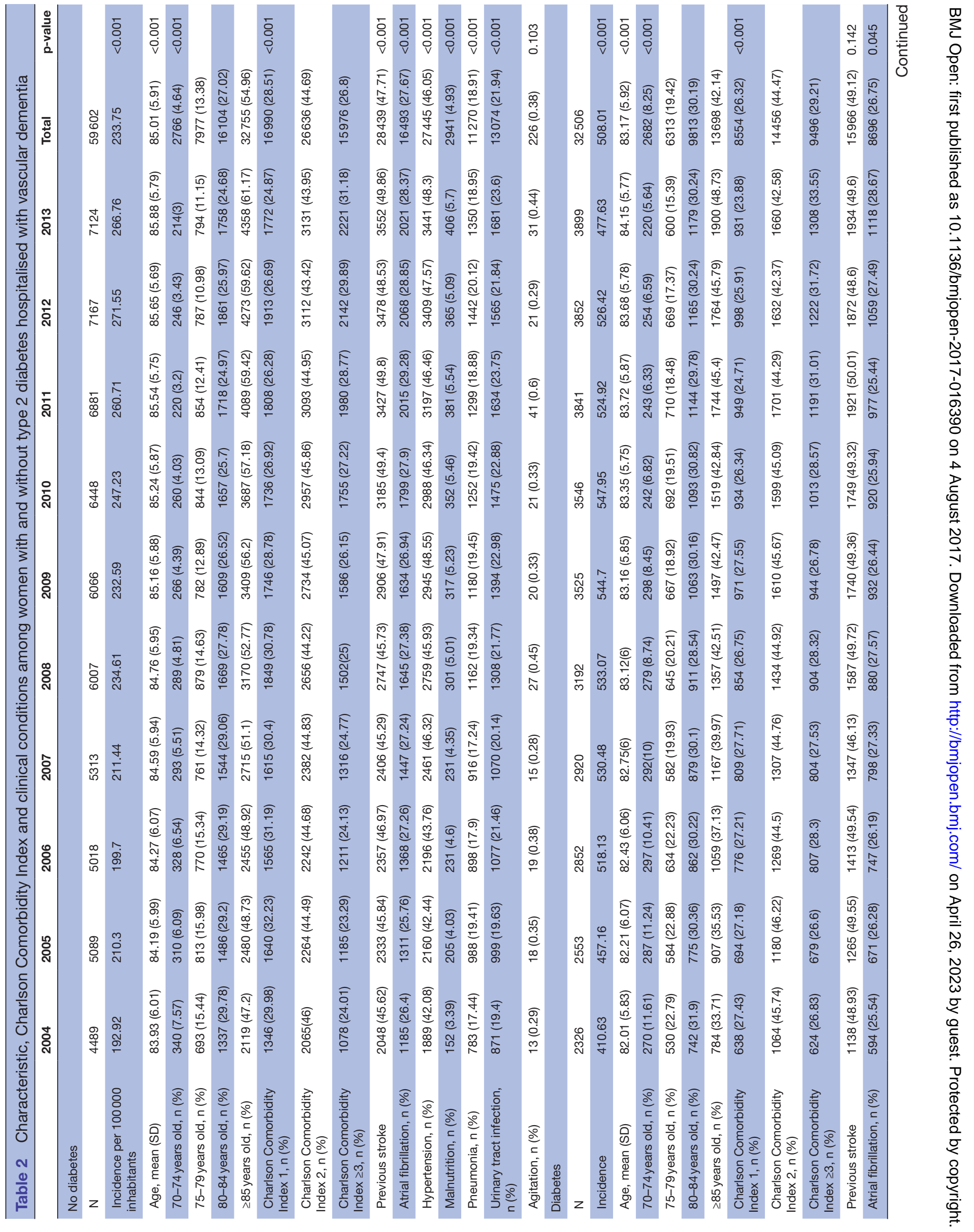


The IHM among men with or without T2DM did not show a significant variation of the study, ranging from $16.62 \%$ to $14.49 \%$ and from $17.08 \%$ to $16.29 \%$, respectively (table 3 ).

The mean LOHS decreased from 9 days in 2004 to 7 days in 2013 in men without diabetes and from eight to 7 days in men with diabetes $(\mathrm{p}<0.05)$. Readmissions remained stable approximately $17 \%$ for patients with diabetes, while they slightly increased in men without diabetes ranging from $14.07 \%$ in 2004 to $14.65 \%$ in 2013 $(\mathrm{p}<0.05)$.

Table 3 shows a significant increase in bladder catheterisation in men with diabetes, raising from $2.82 \%$ in 2004 to $5.69 \%$ in 2013 , and from $3.46 \%$ to $5.56 \%$ in the same period among those without the disease. The use of PEG has remained stable at approximately $1 \%$ of hospitalizations due to $\mathrm{VaD}$, both in diabetic and non-diabetic patients. However, there has been a significant increase in the use of mechanical ventilation in diabetic and non-diabetic men, ranging from $0.41 \%$ and $0.76 \%$ in 2004 to $1.24 \%$ and $1.73 \%$ in 2013 , respectively.

The most commonly used diagnostic procedure was CAT $22.9 \%$ in non-diabetic men and $23.93 \%$ in diabetic ones) followed by magnetic resonance $(3.25 \%$ and $3.74 \%$, respectively). The use of CAT in non-diabetic men has significantly decreased, while it has remained stable in diabetic men over the study period.

The IHM among women with diabetes who had a VaD discharge did not vary significantly over the study period (table 4). However, in women without diabetes the IHM was significantly higher in $2004(16.08 \%)$ than in $2013(14.42 \%)$. Over the decade analysed, the LOHS in women of both groups decreased significantly $(p<0.05)$. We found that readmissions significantly increased in women without diabetes, ranging from $11.63 \%$ in 2004 to $13.64 \%$ in 2013 , while it remained stable over time in the case of women with diabetes.

Akin to our findings in men, we found a significant increase in the utilisation of mechanical ventilation, from $0.39 \%$ to $1.05 \%$ in women suffering T2DM and from $0.67 \%$ to $1.35 \%$ in those without diabetes with $\mathrm{VaD}$ over the period of study. The most used diagnostic procedure was CAT for both female groups. Furthermore, it was more frequently used among women with rather than without diabetes every year analysed. In diabetic women, the use of MRI has increased over time.

The comparison of hospitalisation outcomes between men and women with diabetes revealed higher crude IHM among men $(15.3 \%)$ than women $(14.35 \%)$ in the whole sample, in all the years studied. Readmission rates were also significantly higher among men than women $(17.22 \%$ vs $15.52 \%)$. In men with diabetes, MRI was significantly more used that in women with diabetes (3.74\% vs $2.55 \%)$, and PEG was more frequently used among women with diabetes $(0.94 \%$ vs $0.78 \%)$.

The Poisson regression models yielded an IRR for men with T2DM of 2.14 (95\% CI 2.11 to 2.16). This means that the incidence of $\mathrm{VaD}$ hospitalisations among men with 


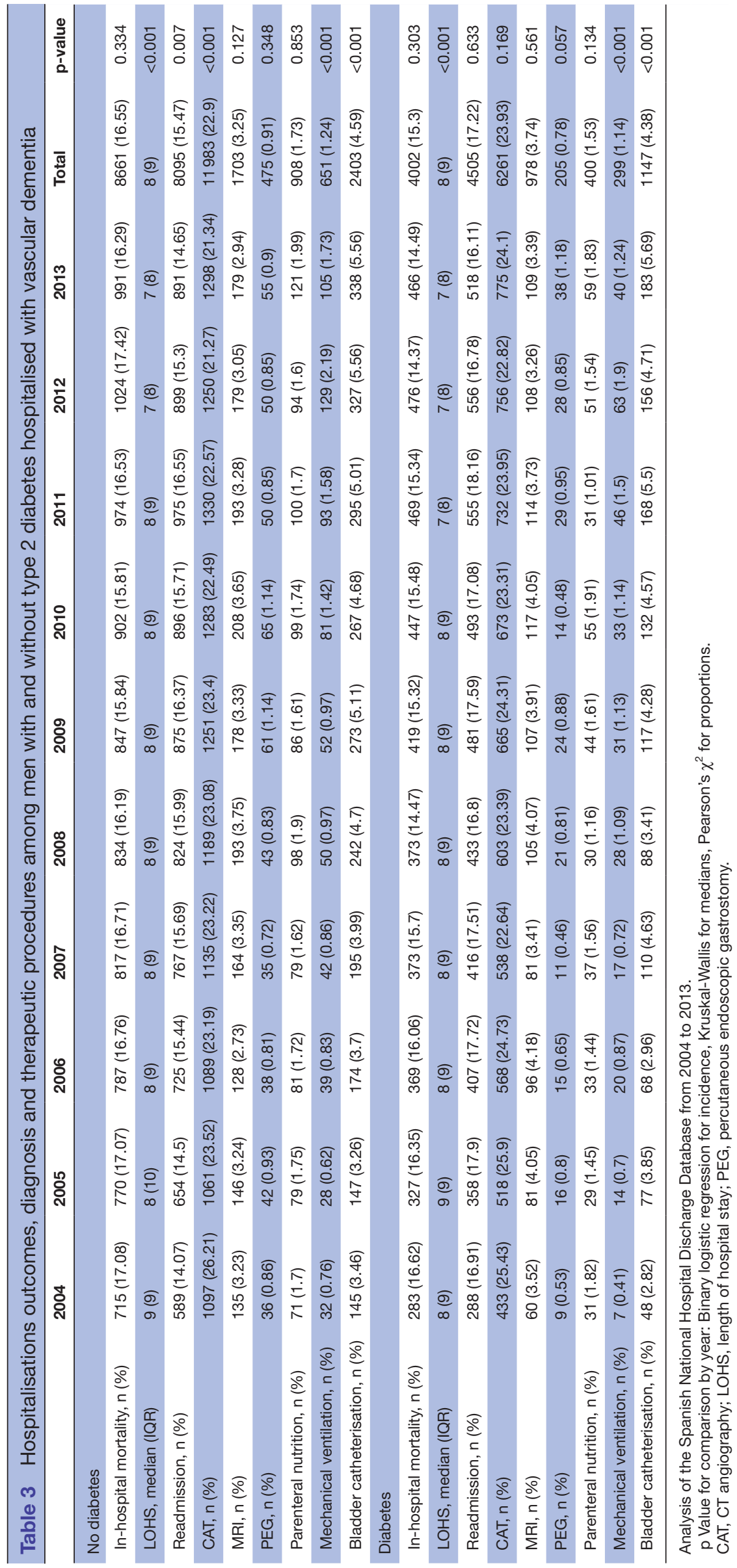




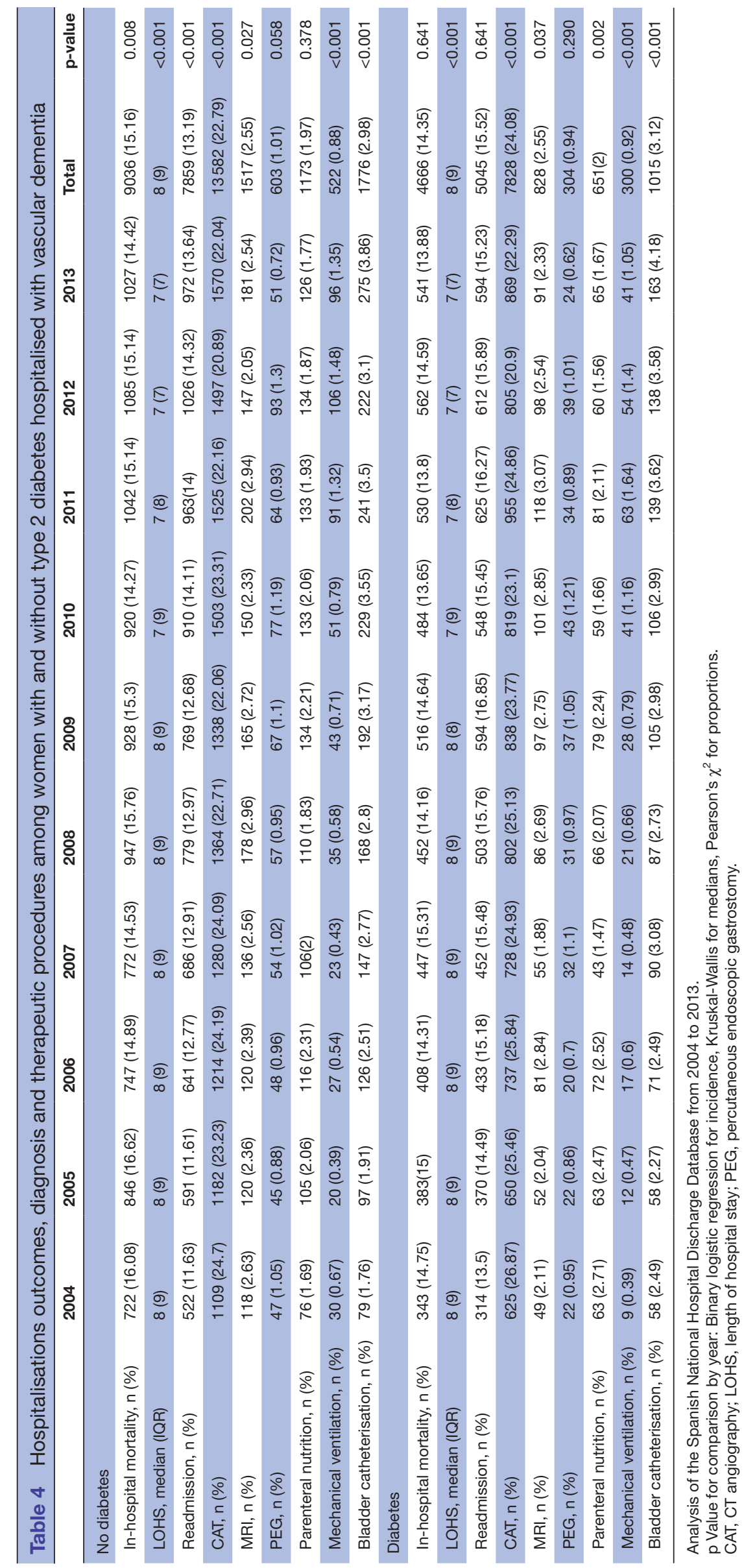


Table 5 Factors associated to in hospital mortality among men and women with and without type 2 diabetes hospitalised with vascular dementia

\begin{tabular}{|c|c|c|c|c|}
\hline & & Men & Woman & Both \\
\hline & & OR (95 Cl\%) & OR (95 Cl\%) & OR (95 Cl\%) \\
\hline Sex & Men & NA & NA & 1.01 (0.98 to 1.04$)$ \\
\hline \multirow[t]{4}{*}{ Age group } & $70-74$ years & 1 & 1 & 1 \\
\hline & $75-79$ years & 1.07 (0.99 to 1.15$)$ & 1.11 (1.01 to 1.23$)$ & 1.08 (1.052 to 1.15$)$ \\
\hline & $80-84$ years & 1.24 (1.15 to 1.33 ) & 1.24 (1.13 to 1.37$)$ & 1.24 (1.17 to 1.31$)$ \\
\hline & $\geq 85$ years & 1.48 (1.38 to 1.59$)$ & 1.54 (1.40 to 1.69$)$ & 1.51 (1.42 to 1.60$)$ \\
\hline \multirow{3}{*}{$\begin{array}{l}\text { Charlson Comorbidity } \\
\text { Index }\end{array}$} & 1 & 1 & 1 & 1 \\
\hline & 2 & 1.11 (1.05 to 1.17$)$ & 1.23 (1.17 to 1.29$)$ & 1.18 (1.13 to 1.22$)$ \\
\hline & $3+$ & 1.35 (1.27 to 1.42$)$ & 1.62 (1.54 to 1.70$)$ & 1.49 (1.43 to 1.54$)$ \\
\hline Atrial fibrillation & & 1.15 (1.09 to 1.20$)$ & 1.21 (1.16 to 1.26$)$ & 1.18 (1.15 to 1.22$)$ \\
\hline Hypertension & & 0.83 (0.80 to 0.87 ) & 0.87 (0.84 to 0.90$)$ & 0.85 (0.83 to 0.87$)$ \\
\hline Malnutrition & & 0.91 (0.83 to 1.00$)$ & 0.91 (0.83 to 0.99$)$ & 0.91 (0.85 to 0.97$)$ \\
\hline Pneumonia & & 2.55 (2.44 to 2.65 ) & 2.64 (2.53 to 2.75$)$ & 2.59 (2.52 to 2.67$)$ \\
\hline Urinary tract infection & & 0.85 (0.81 to 0.90$)$ & 0.79 (0.75 to 0.83$)$ & 0.82 (0.79 to 0.85$)$ \\
\hline LOHS (days) & & 0.98 (0.97 to 0.99 ) & 0.98 (0.97 to 0.99$)$ & 0.98 (0.97 to 0.99$)$ \\
\hline Readmission & & 1.45 (1.38 to 1.52 ) & 1.38 (1.31 to 1.44$)$ & 1.41 (1.36 to 1.46$)$ \\
\hline CAT & & 0.69 (0.66 to 0.73 ) & 0.67 (0.64 to 0.71$)$ & 0.68 (0.66 to 0.71$)$ \\
\hline MRI & & 0.37 (0.31 to 0.45 ) & 0.25 (0.20 to 0.32$)$ & 0.32 (0.27 to 0.37$)$ \\
\hline PEG & & 0.44 (0.34 to 0.57 ) & 0.32 (0.24 to 0.42$)$ & 0.37 (0.31 to 0.45$)$ \\
\hline Parenteral nutrition & & 1.45 (1.27 to 1.66$)$ & 1.17 (1.03 to 1.32$)$ & 1.29 (1.18 to 1.41$)$ \\
\hline Mechanical ventilation & & 2.98 (2.59 to 3.43 ) & 2.67 (2.29 to 3.11$)$ & $2.83(2.55$ to 3.14$)$ \\
\hline Type 2 diabetes & & 0.99 (0.95 to 1.04$)$ & 1.01 (0.97 to 1.05$)$ & 1.00 (0.98 to 1.03$)$ \\
\hline Year & & 0.97 (0.96 to 0.98$)$ & 0.97 (0.96 to 0.98$)$ & 0.97 (0.96 to 0.98$)$ \\
\hline
\end{tabular}

Analysis of the Spanish National Hospital Discharge Database from 2004 to 2013.

CAT, CT angiography; LOHS, length of hospital stay; PEG, percutaneous endoscopic gastrostomy

diabetes was two times higher than among men without, when all other possible confounding variables were controlled. The corresponding figure for women was 2.22 (95\% CI 2.19 to 2.25$)$.

As can be seen in table 5 , for both gender, the IHM was higher in older subjects (OR 1.54; $95 \%$ CI 1.40 to 1.69 and OR $1.48 ; 95 \%$ CI 1.38 to 1.59 in $\geq 85$ aged group in comparison with 70-74 years that was used as the reference category). The IHM was significantly higher in subjects with diabetes suffering more comorbidities (OR $1.35 ; 95 \% \mathrm{CI}, 1.27$ to 1.42 and OR $1.62 ; 95 \% \mathrm{CI}, 1.54$ to 1.70 for those men and women with $\geq 3$ comorbidities).

IHM was associated with pneumonia (OR 2.5; 95\% CI 2.44 to 2.65 in men and OR 2.64; $95 \%$ CI 2.53 to 2.75 in women) and in atrial fibrillation sufferers (OR 1.15; $95 \%$ CI 1.09 to 1.20 in men and OR $1.21 ; 95 \%$ CI 1.16 to 1.26 in women).

The men and women with diabetes who required mechanical ventilation showed higher probabilities of dying (2.98-fold and 2.67-fold, respectively) compared with patients who did not require this procedure. The use of PEG was associated with a reduced IHM among both men and women with diabetes and admitted for $\mathrm{VaD}$ (OR $0.44 ; 95 \%$ CI 0.34 to 0.45 and OR $0.32 ; 95 \%$ CI 0.24 to 0.42 , respectively). In contrast, patients who received parenteral nutrition were more likely to die during their stay (OR 1.45; 95\% CI 1.27 to 1.66 and OR 1.17 ; $95 \%$ CI 1.03 to 1.32 , respectively).

The time-trend analysis revealed a significant reduction in IHM between 2004 and 2013 in patients with diabetes (OR 0.97; 95\% CI 0.96 to 0.98). The analysis of the whole database, and after multivariable adjustment, revealed that suffering from diabetes was not a predictor of IHM in any gender (OR 0.99; $95 \%$ CI 0.95 to 1.04 in men and OR $1.01 ; 95 \%$ CI 0.97 to 1.05 in women).

\section{DISCUSSION}

In this study of more than 170000 admissions for $\mathrm{VaD}$, we found that the prevalence of T2DM among men and women hospitalised has increased over time in all age groups. This finding is not surprising because the prevalence of diabetes and dementia are both rapidly increasing. $^{26}$ 
A number of epidemiological studies to date have focused on the association between diabetes and the risk of dementia. Ohara et $a l^{15}$ reported an increase in the prevalence of all-cause dementia in the Japanese population, and diabetes was also identified as a significant risk factor. Growing evidence supporting a biological relationship between diabetes and VaD suggests a multifactorial pathogenesis that involves vascular changes, hyperglycaemic toxicity, insulin metabolism and chronic inflammation. ${ }^{16}{ }^{17}$ Diabetes represents a well-established risk factor for macrovascular and microvascular complications such as stroke ${ }^{18}$; this suggests that there is a robust association between diabetes and $\mathrm{VaD}$, that is, one that is not a consequence of confounding. In our study, age was the most strongly associated factor for $\mathrm{VaD}$, and patients with diabetes were significantly younger than those without. Previous research has shown that patients with both VaD and T2DM have a significantly earlier onset of $\mathrm{VaD}$, a faster rate of cognitive decline and a greater prevalence of neuropsychiatric symptoms than patients with VaD alone. ${ }^{19}$ In our study we found, as expected, a higher prevalence of hypertension among patients with diabetes compared with those without. It has been reported that arterial stiffness and small vessel disease can predict future cognitive decline in elderly people with T2DM. ${ }^{20}$ Over time, we found that subjects admitted to the hospital with $\mathrm{VaD}$ were progressively older, with increasing comorbid conditions and more hospital readmissions, which highlight the increasing frailty of these patients. A link between comorbidity and the risk of dementia in patients with diabetes has also been published. ${ }^{21}$ It seems necessary that to reduce the medical and social financial burden associated with dementia, the focus should be on chronic disease prevention.

Infections, diabetes or their complications have been highlighted as common reasons for hospital admission in patients with dementia. ${ }^{22}$ In our study, pneumonia and urinary tract infections significantly increased over the study period. The use of bladder catheterisation has significantly increased over time, which can contribute to the higher observed prevalence of urinary tract infections, but they are not associated with higher mortality. However, pneumonia is one of the infectious complications that has significantly increased over the study period and is also associated with a worse prognosis. The use of mechanical ventilation has also significantly increased, and it is also associated with higher IHM. This finding is relevant because it seems to be a bidirectional relationship: hospitalisation with pneumonia has been associated with dementia and persistent cognitive dysfunction with severe infections. ${ }^{23}$ On the other hand, dysphagia occurs frequently in patients with dementia and is related to aspiration pneumonia. Interestingly, we have found lower mortality in patients fed by PEG. This protective effect could be associated with a better nutritional and hydration status and potentially lower rates of aspiration pneumonia, but this is only a hypothesis because our study design is not appropriate to assess the association between PEG and pneumonia. Furthermore, there is controversial evidence on this issue. A study by Finucane et al was unable to find data suggesting that tube feeding of subjects with advanced dementia was useful to prevent aspiration pneumonia, lengthened survival or provided palliation, ${ }^{24}$ while Nakajoh et al compared incidence of pneumonia in stroke subjects who also suffered dysphagia finding lower rates in those with tube feeding than in those orally fed $(13.2 \%$ vs $54.3, \mathrm{p}<0.001){ }^{25}$

As has been described previously for ischaemic and haemorrhagic stroke, we did not find an increased IHM due to $\mathrm{VaD}$ in patients with diabetes compared with those without the disease. ${ }^{18}{ }^{26}$ Although obesity is accepted to be a major risk factor for the development of cardiovascular diseases and diabetes, a higher BMI may be related to a lower mortality and improved outcome in a number of chronic diseases. ${ }^{27-29}$ Over the past decade, many research has shown that individuals, especially those of older ages, who have several comorbid chronic diseases and a high body mass index (BMI) may have lower figures of all-cause and cardiovascular mortality compared with normal-weight subjects. ${ }^{27}$ This observation has been referred to as 'the obesity paradox'. ${ }^{28}{ }^{29}$ Possibly, the protective effect of the nutritional status in older individuals who are overweight and obese and the negative health effects of undernutrition in non-overweight individuals are partly responsible for this paradox. Although unfortunately in our study the BMI of patients admitted for $\mathrm{VaD}$ was not registered, this could be a possible explanation. This hypothesis concerning a better nutritional status is consistent with the better outcomes described above in those patients undergoing PEG.

Our study has several strengths, including the large sample, the 10-year follow-up and use of standardised methods. ${ }^{30}$ However, this study is not exempt from limitations. In the first place, the CMBD includes administrative discharge data and is based on data that the physician recorded in the discharge report. Therefore, we lack information on relevant variables that may act as confounders, such as VaD or T2DM duration or treatments for this last condition, among others. Calculation of incidence on the basis of a database without any access to sociodemographic variables is another limitation.

A further important limitation is the lack of specificity of clinically defined $\mathrm{VaD}$. The cognitive impairment observed in $\mathrm{VaD}$ and $\mathrm{AD}$ plus atherosclerosis might overlap extensively. Thus, it would be advisable to consider other databases, such as mortality registries, in addition to discharge data, to help detect patients with $\mathrm{VaD}$ who die outside of hospital, especially at nursing homes. Unfortunately, such resources are currently unavailable for us in Spain.

Finally, as we state in the ethics section, patient identifiers were removed prior to our accessing the database, for the purpose of protecting patient anonymity, thus it is impossible to identify individual patients, either in this paper or in the database. Therefore, it is impossible for us to select a sample of study participant and to identify their 
medical records to validate the $\mathrm{VaD}$ and T2DM diagnosis because we do not know in which hospital the participant was admitted.

Van de Vorst et al compared the ICD-9-CM codes for VaD with medical records in the Dutch Hospital Discharge Register and concluded that the validity is high. For VaD the positive predictive Value (PPV) was of $91.3 \%(95 \%$ CI $72.0 \%$ to $98.8 \%$ ), and no significant differences were found in PPV according to age, sex, the diagnostic setting and comorbid conditions. ${ }^{31}$

Regarding the validity of the diabetes diagnosis, a recent review and meta-analysis based on the reports of six studies found that a common administrative database definition for diabetes had a pooled specificity of $97.9 \%$ and a sensitivity of $82.3 \% .^{32}$

In Canada, Kokotailo et al found that, among patients with stroke, when compared with hospital medical record, the ICD-9-CM diagnosis of DM in the discharge report had a sensitivity of $94 \%$ (95\% CI $69 \%$ to $99 \%$ ) and a specificity of $98 \%$ (95\% CI $91 \%$ to $99 \%$ ). ${ }^{33}$

\section{CONCLUSIONS}

Our findings reveal a significant increase of the incidence of suffering from VaD during the study period. Men and women with T2DM display more than double the risk of VaD admissions after adjustment for other risk factors. Patients admitted with VaD were progressively older and had multiple comorbidities. Pneumonia was associated with poorer prognosis, and the use of PEG was associated with reduced mortality. Diabetes was not associated with IHM, and the time trends show that mortality is decreasing over time.

\section{Author affiliations}

${ }^{1}$ Department of Internal Medicine, Hospital Universitario Infanta Leonor, Madrid, Spain

${ }^{2}$ Department of Internal Medicine, Hospital Universitario Clínico San Carlos, Madrid, Spain

${ }^{3}$ Department of Internal Medicine, Hospital General Universitario Gregorio Marañón, Madrid, Spain

${ }^{4}$ Preventive Medicine and Public Health Teaching and Research Unit, Health Sciences Faculty, Rey Juan Carlos University, Madrid, Spain

${ }^{5}$ Department of Respiratory Care, Hospital General Universitario Gregorio Marañón, Madrid, Spain

Acknowledgements The authors gratefully acknowledge the cooperation of the Spanish Ministry of Health and Social Policy for providing access to the records of the Minimum Basic Data Set (CMBD).

Contributors NMR, RJG and ALdA researched data, contributed to the discussion, wrote the manuscript and reviewed/edited the manuscript. VHB researched data and reviewed/edited the manuscript. NMR, MMB, JMdMY, JdMD, RJG and ALdA contributed to the discussion and reviewed/edited the manuscript. All authors reviewed and gave their final approval of the version to be submitted.

Funding This study received funding by the FIS (Fondo de Investigaciones Sanitarias - Health Research Fund, grants no. Pl13/00118 \& Pl16/00564, Instituto de Salud Carlos III) co financed by the European Union through the Fondo Europeo de Desarrollo Regional (FEDER, 'Una manera de hacer Europa') and by the Grupo de Excelencia Investigadora URJC-Banco Santander No. 30VCPIGI03: Investigación traslacional en el proceso de salud-enfermedad (ITPSE). The funders had no role in study design, data collection and analysis, decision to publish or preparation of the manuscript.
Competing interests None declared.

Ethics approval Universidad Rey Juan Carlos.

Provenance and peer review Not commissioned; externally peer reviewed.

Data sharing statement We sign a contract with the Spanish Ministry of Health who provides us with the database. In that contract we have to sign that the database would not be shared with other investigators and that it would be destroyed once the investigation was concluded.

Open Access This is an Open Access article distributed in accordance with the Creative Commons Attribution Non Commercial (CC BY-NC 4.0) license, which permits others to distribute, remix, adapt, build upon this work non-commercially, and license their derivative works on different terms, provided the original work is properly cited and the use is non-commercial. See: http://creativecommons.org/ licenses/by-nc/4.0/

(c) Article author(s) (or their employer(s) unless otherwise stated in the text of the article) 2017. All rights reserved. No commercial use is permitted unless otherwise expressly granted.

\section{REFERENCES}

1. Prince M, Bryce R, Albanese E, et al. The global prevalence of dementia: a systematic review and metaanalysis. Alzheimers Dement 2013;9:63-75.

2. World Health Organization. Dementia. http://www.who.int/ mediacentre/factsheets/fs362/en/ (Accessed February 10, 2017).

3. Arvanitakis Z, Capuano AW, Leurgans SE, et al. Relation of cerebral vessel disease to Alzheimer's disease dementia and cognitive function in elderly people: a cross-sectional study. Lancet Neurol 2016;15:934-43.

4. Verdelho A, Madureira S, Ferro JM, et al. Differential impact of cerebral white matter changes, diabetes, hypertension and stroke on cognitive performance among non-disabled elderly. the LADIS study. J Neurol Neurosurg Psychiatry 2007;78:1325-30.

5. Launer LJ. Diabetes and brain aging: epidemiologic evidence. Curr Diab Rep 2005;5:59-63.

6. World Health Organization. Global Report on Diabetes. http://apps. who.int/iris/bitstream/10665/204871/1/9789241565257_eng.pdf (Accessed February 10, 2017).

7. Sato N, Morishita R. Brain alterations and clinical symptoms of dementia in diabetes: aß/tau-dependent and independent mechanisms. Front Endocrinol 2014:5:1-8.

8. Bordier L, Doucet J, Boudet J, et al. Update on cognitive decline and dementia in elderly patients with diabetes. Diabetes Metab 2014;40:331-7.

9. Li W, Huang E. An Update on type 2 Diabetes Mellitus as a risk factor for Dementia. J Alzheimers Dis 2016;53:393-402.

10. Lu FP, Lin KP, Kuo HK. Diabetes and the risk of multi-system aging phenotypes: a systematic review and meta-analysis. PLoS One 2009; 4:e4144.

11. Chatterjee S, Peters SA, Woodward M, et al. Type 2 Diabetes as a risk factor for Dementia in Women compared with men: a pooled analysis of 2.3 Million people comprising more than 100,000 cases of Dementia. Diabetes Care 2016;39:300-7.

12. Fei M, Yan Ping Z, Ru Juan M, et al. Risk factors for dementia with type 2 diabetes mellitus among elderly people in China. Age Ageing 2013;42:398-400.

13. Instituto Nacional de Gestión Sanitaria, Ministerio de Sanidad, Servicios Sociales e Igualdad. Conjunto Mínimo Básico de Datos, Hospitales del INSALUD http://www.ingesa.msc.es/estadEstudios/ documPublica/CMBD-2001.htm (Accessed February 10, 2017).

14. Charlson ME, Pompei $\mathrm{P}$, Ales KL, et al. A new method of classifying prognostic comorbidity in longitudinal studies: development and validation. J Chronic Dis 1987;40:373-83.

15. Ohara T. Epidemiology of diabetes and risk of dementia. Brain Nerve 2016;68:719-27.

16. Ninomiya T. Diabetes mellitus and dementia. Curr Diab Rep 2014;14:487.

17. Ahtiluoto S, Polvikoski T, Peltonen M, et al. Diabetes, Alzheimer disease, and vascular dementia: a population-based neuropathologic study. Neurology 2010;75:1195-202.

18. Muñoz-Rivas N, Méndez-Bailón M, Hernández-Barrera V, et al. Time Trends in ischemic stroke among type 2 Diabetic and Non-Diabetic patients: analysis of the Spanish National Hospital Discharge Data (2003-2012). PLoS One 2015;10:e0145535.

19. Murthy SB, Jawaid A, Qureshi SU, et al. Does diabetes mellitus alter the onset and clinical course of vascular dementia? Behav Neurol 2010;23:145-51. 
20. Brundel M, van den Heuvel M, de Bresser J, et al. Utrecht Diabetic Encephalopathy Study Group. cerebral cortical thickness in patients with type 2 diabetes. J Neurol Sci 2010;299:126-30.

21. Kuo SC, Lai SW, Hung HC, et al. Association between comorbidities and dementia in diabetes mellitus patients: populationbased retrospective cohort study. J Diabetes Complications 2015;29:1071-6.

22. Chang CC, Lin PH, Chang YT, et al. The impact of admission diagnosis on recurrent or frequent hospitalizations in 3 dementia subtypes: a hospital-based cohort in Taiwan with 4 years longitudinal follow-ups. Medicine (Baltimore) 2015;94:e 2091.

23. Tate JA, Snitz BE, Alvarez KA, et al. Infection hospitalization increases risk of Dementia in the Elderly*. Crit Care Med 2014;42:1037-46.

24. Finucane TE, Christmas C, Travis K. Tube feeding in patients with advanced dementia: a review of the evidence. JAMA 1999;282:1365-70.

25. Nakajoh K, Nakagawa T, Sekizawa K, et al. Relation between incidence of pneumonia and protective reflexes in post-stroke patients with oral or tube feeding. J Intern Med 2000;247:39-42.

26. Muñoz-Rivas N, Méndez-Bailón M, Hernández-Barrera V, et al. Type 2 Diabetes and hemorrhagic stroke: a Population-Based study in Spain from 2003 to 2012. Journal of Stroke and Cerebrovascular Diseases 2016;25:1431-43.
27. Hainer V, Aldhoon-Hainerova I. Obesity Paradox does Exist. Diabetes Care 2013;36:S276-S281.

28. Kalantar-Zadeh K, Block G, Horwich T, et al. Reverse epidemiology of conventional cardiovascular risk factors in patients with chronic heart failure. J Am Coll Cardiol 2004;43:1439-44.

29. Gruberg L, Weissman NJ, Waksman R, et al. The impact of obesity on the short-term andlong-term outcomes after percutaneous coronary intervention: the obesity paradox? J Am Coll Cardiol 2002;39:578-84.

30. Lopez-de-Andres A, Jimenez-García R, Hernandez-Barrera V, et al. National trends in utilization and outcomes of coronary revascularization procedures among people with and without type 2 diabetes in Spain (2001-2011). Cardiovasc Diabetol 2014;13:3.

31. van de Vorst IE, Vaartjes I, Sinnecker LF, et al. The validity of national hospital discharge register data on dementia: a comparative analysis using clinical data from a university medical centre. Neth $\mathrm{J}$ Med 2015;73:69-75.

32. Leong A, Dasgupta K, Bernatsky S, et al. Systematic review and Meta-Analysis of Validation studies on a Diabetes Case Definition from Health Administrative Records. PLoS One 2013;8:e75256.

33. Kokotailo RA, Hill MD. Coding of stroke and stroke risk factors using International Classification of Diseases, Revisions 9 and 10. Stroke 2005;36:1776-81. 